\title{
Comparison of Lateral Pinning and Cross Pinning Results in Pediatric Distal Humerus Supracondylar Gartland Type 3 Fractures
}

\author{
Muhammet Salih Ayas ${ }^{1}\left(\mathbb{D}\right.$, Kerim Öner ${ }^{2}$ (D) \\ 1 Erzurum Regional Training and Research Hospital, Department of Orthopedics and Traumatology, Erzurum, Turkey \\ 2 Karadeniz Technical University, Department of Orthopedics and Traumatology, Trabzon, Turkey
}

\begin{abstract}
Background: In this study, we aimed to evaluate the functional outcomes and complications of Gartland type 3 patients treated with lateral pinning and cross pinning in children aged between five and ten years.

Methods: Seventy-four fractures participated in the study, and the data were analyzed. Patients in the lateral pinning group (n:41) were treated with the lateral entry pin alone, and patients in the cross pinning group (n:33) were treated with a combination of 2 lateral entry pins and one medial entry pin. Age, gender, fractured side, Vong Baker pain scale score, duration of surgery, postoperative complications, surgical approach, direction of pin application (lateral or cross), and Modified Flynn grading system grade was noted.

Results: No statistically significant difference was found between lateral pinning and crossed pinning groups in terms of the grade of the Modified Flynn grading system and complications (iatrogenic ulnar nerve damage, loss of reduction, and superficial infection) (respectively, p: 0.138 and p: 0.991).

Conclusion: When both techniques were performed carefully, successful clinical results were observed. If the surgeon detects intraoperative instability, s/he should not hesitate to pin the medial K-wire in order to increase stability.

Keywords: Pediatric Fractures, Supracondylar Humerus Fractures, Cross Pinning, Lateral Pinning.

\section{INTRODUCTION}

Pediatric distal humerus supracondylar fractures are the most common fractures that account for more than $50 \%$ of fractures around the elbow in children (1). Classically, these injuries are divided into extension and flexion types. The extension type is the most common type (2). The most widely accepted classification of pediatric distal humeral

(3). While type I fractures are typically treated nonsurgically, some type II and almost all type III fractures usually require surgical intervention (4). Closed reduction and percutaneous pinning is the universally accepted treatment modality for displaced pediatric distal humerus supracondylar fractures. Pin configuration has been the focus of many recent research studies on the treatment of type 3 fractures (5-7).
\end{abstract} supracondylar fractures is the Gartland classification 
There are two common pin fixing techniques: lateral pinning only and cross pinning with at least one medial and at least one lateral (8). Theoretically, cross-entry pins have the advantage of improved mechanical stability of the configuration, however, this technique increases potential injury to the ulnar nerve $(9,10)$. Although injury to the ulnar nerve can be avoided, only lateral entry pins can reduce the mechanical stability of the structure (11). Biomechanical tests have shown that both medial and lateral cross pinning is more advantageous $(12,13)$. Nevertheless, the risk of iatrogenic ulnar nerve injury during medial pin placement preoccupies surgeons in medial pin placement (14).

In this study, it was aimed to analyze the functional outcomes and complications of Gartland type 3 patients aged between five and ten years who were treated with lateral pinning and cross pinning.

\section{MATERIALS AND METHODS}

This study was approved by the Erzurum Regional Training and Research Hospitals' local ethics committee (Date: 21.06.2021 No: KAEK 2021/12-199), and the study was conducted according to the Declaration of Helsinki 1975. Between May 2017 and May 2020, 99 patients with pediatric distal humerus supracondylar fractures who were hospitalized and planned for surgery were identified. Inclusion criteria were defined as; patients with a Gartland type 3 supracondylar fracture, aged between five and ten years, and at least 12 weeks of follow-up. Patients who had multiple fractures at the time of injury (n:11), whose data could not be accessed (n:8), and whose follow-up was delayed (n:7) were excluded from the study. After applying our criteria, the medical data of 74 patients ( 31 boys and 43 girls, mean age $7.08 \pm 1.42$ ) who underwent surgery for a Gartland type III pediatric distal humerus supracondylar fracture were documented and analyzed retrospectively.

The recorded data were as follows; age, gender, fractured side (right or left), vong Baker pain scale score, operation time, postoperative complications, surgical approach, number of pins, direction of pin application (lateral or cross), and Modified Flynn grading system grade.

\section{Surgical technique}

All interventions were performed under general anesthesia by a surgical team working in the same clinic. A closed reduction maneuver was performed to all fractures, and patients who could not achieve closed reduction underwent open surgery with a lateral approach. An anterior open approach was performed to patients with preoperative anterior interosseous nerve (median nerve) injury. After reduction, it was stabilized in the reduction position provided under the scope with two or four percutaneous K-wires (k-wires determined according to the patient's age and bone cortex thickness). Two K-wires were placed laterally as standard procedure. A third K-wire was placed medially in a mini-open not exceeding a total of $3 \mathrm{~K}$-wires, with stability assessed by the intraoperative $\mathrm{C}$-arm fluoroscopy system. After the wires were cut, the ends were bent and left on the skin. After the K-wire dressing, the elbow joint was splinted to be immobilized in neutral rotation and $90^{\circ}$ flexion position for three weeks.

Postoperative follow-up was made routinely, radiologically, and clinically at the first, second, third, fourth, sixth, eighth, twelfth, twenty-fourth weeks and at the end of the first year. The splint was terminated in the third week. Active movements were encouraged by teaching the child and family without removing the K-wires. In the fourth week, the K-wires were removed in the orthopedic clinic. Active-passive movements of the elbow were started. Exhausting - demanding activities were restricted for another four weeks.

Pain assessment was performed with the Wong-Baker Faces Pain Rating Scale preoperatively and at the 12thweek clinical examination (15). The children were asked to choose the facial expression that best described their pain.

Evaluation of clinical results was made with the modified Flynn grading system at 12 weeks and at the end of the first year $(16,17)$. Modified Flynn grading system's criteria include two factors: Cosmetic factor (loss of carrying angle degree) and functional factor (motion loss in degrees). Results were grouped into satisfactory [Excellent (0 to 5) - Good (6 to 10)] / Unsatisfactory [Fair (11 to 15) - Poor $(>15)]$. The final modified Flynn grade result was noted according to whichever cosmetic or functional factor was worse (18). The range of motion of the joint was measured with the goniometer. Measurements were made considering passive movements. Restoration of a full range of motion of the elbow was defined as the range of elbow flexion/extension less than $5^{\circ}$ as measured by the uninjured elbow (19). 


\section{Statistical Analysis}

While making the statistics of the study, numerical data were given as mean and standard deviation, and categorical data were given as numbers and percentages in descriptive statistics. The distribution of numerical data was analyzed with histogram graphics. Student t-test and Mann-Whitney U test were used after checking the suitability of the numerical data to the normal distribution in two separate groups. Chi-square and Fisher's Exact test were used to compare categorical data. P significance value was accepted as 0.05 . SPSS 23.0 package program was used in the analysis.

Table 1. Analysis of demographic data

\section{RESULTS}

A total of 74 people were included in the study. While 41 of the patients were in the lateral pinning group, 33 of them were in the cross pinning group ( Figure 1.). The mean age of all patients was 7.08 \pm 1.42 . No significant age difference was observed between the groups in the study (p: 0.173). $41.9 \%$ (n:31) of the patients were female and $58.1 \%$ (n:43) were male. In the study, no significant difference was observed between the groups in terms of gender ( $p: 0.302$ ). There was no significant difference between the groups in terms of parties (p: 0.898). Some descriptive data of the patients and the differences between the groups are given in Table 1. In the study, no statistically significant difference was found between the groups in terms of Modified Flynn grading system, Common Modified Flynn grading system, and complications (respectively; p: 0.138 and p: 0.991) (Table 1).

\begin{tabular}{|c|c|c|c|c|}
\hline Features & & $\begin{array}{l}\text { Lateral pinning } \\
\text { group (n:41) }\end{array}$ & $\begin{array}{l}\text { Cross pinning group } \\
(\mathrm{n}: 33)\end{array}$ & $\mathrm{p}$ \\
\hline Age (Mean \pm SD ) & & $6.88 \pm 1.52$ & $7.33 \pm 1.26$ & 0.173 \\
\hline \multirow[t]{2}{*}{ Gender } & Girl & 26 & 17 & \multirow[t]{2}{*}{0.302} \\
\hline & Boy & 15 & 16 & \\
\hline \multirow[t]{2}{*}{ Side } & Right & 18 & 14 & \multirow[t]{2}{*}{0.898} \\
\hline & Left & 23 & 19 & \\
\hline \multirow{2}{*}{$\begin{array}{l}\text { Preoperative neurological } \\
\text { examination }\end{array}$} & No & 39 & 32 & \multirow[t]{2}{*}{0.689} \\
\hline & Anterior interosseous nerve injury & 2 & 1 & \\
\hline \multirow[t]{2}{*}{ Surgical approach } & Closed & 29 & 26 & \multirow[t]{2}{*}{0.430} \\
\hline & Open & 12 & 7 & \\
\hline \multirow[t]{3}{*}{ Surgical approach in detail } & Closed & 29 & 26 & \multirow[t]{3}{*}{0.397} \\
\hline & Anterior & 2 & 0 & \\
\hline & Lateral & 10 & 7 & \\
\hline \multirow[t]{2}{*}{ Complication } & Yes & 4 & 4 & \multirow[t]{2}{*}{0.745} \\
\hline & No & 37 & 29 & \\
\hline \multirow[t]{4}{*}{ Complications in detail } & No & 37 & 29 & \multirow[t]{4}{*}{0.991} \\
\hline & Iatrogenic ulnar injury & 1 & 1 & \\
\hline & Reduction loss & 1 & 1 & \\
\hline & Superficial infection & 2 & 2 & \\
\hline \multirow[t]{2}{*}{ Fracture type } & Flexion & 2 & 1 & \multirow[t]{2}{*}{0.689} \\
\hline & Extension & 39 & 32 & \\
\hline \multirow{4}{*}{$\begin{array}{l}\text { Modified Flynn grading system } \\
\text { results in detail }\end{array}$} & Excellent & 32 & 19 & \multirow[t]{4}{*}{0.138} \\
\hline & Good & 7 & 8 & \\
\hline & Fair & 2 & 5 & \\
\hline & Poor & 0 & 1 & \\
\hline \multirow{2}{*}{$\begin{array}{l}\text { Modified Flynn grading system } \\
\text { results }\end{array}$} & Satisfactory & 39 & 27 & \multirow[t]{2}{*}{0.067} \\
\hline & Unsatisfactory & 2 & 6 & \\
\hline
\end{tabular}


There was no significant difference between the groups in terms of operation time (min), Preop vong Baker pain scores, and Postop vong Baker pain scores (Table 2).

Table 2. Comparison of operation time and pain score results between groups

\begin{tabular}{|l|r|r|r|r|r|r|r|r|r|}
\hline \multirow{2}{*}{} & \multicolumn{9}{|c|}{ Groups } \\
\cline { 2 - 11 } & \multicolumn{4}{|c|}{ Lateral pinning group (n:41) } & \multicolumn{3}{c|}{ Cross pinning group (n:33) } \\
\cline { 2 - 11 } & Min. & Max & Mean & SS & Min. & Max. & Mean & SS \\
\hline Age & 5 & 9 & 6.88 & 1.52 & 5 & 9 & 7.33 & 1.26 & 0.173 \\
\hline Operation time (min) & 20 & 75 & 31.68 & 10.92 & 19 & 65 & 35.85 & 12.03 & 0.203 \\
\hline Wong-Baker Scale Score & 6 & 10 & 7.17 & 1.26 & 6 & 10 & 7.27 & 1.48 & 0.904 \\
\hline Wong-Baker Scale Score & 0 & 2 & 0.10 & 0.43 & 0 & 2 & 0.18 & 0.58 & 0.476 \\
\hline
\end{tabular}

\section{DISCUSSION}

Pediatric distal humerus supracondylar fractures are the most common injuries around the elbow and usually occur in the first decade of life (20). The treatment of displaced pediatric distal humerus supracondylar fractures is surgery. There is no accurate consensus on the appropriateness of the optimal K-wire configuration technique $(12,13,21)$. The two most preferred techniques are the cross K-wire or just lateral K-wire techniques $(5,6)$. In our study, we also did not find a statistical difference between lateral pinning and cross pinning in terms of functional results and complications in Gartland type 3 distal humerus supracondylar fractures in children aged between five and ten years.

Cross pin fixation of a pediatric distal humerus supracondylar fracture was first described in 1948 (22). Although there is a risk of iatrogenic ulnar nerve injury in this technique, the cross K-wire pinning technique continues to be used today with excellent results and low morbidity $(5,6,11)$. We consider that the average of $5 \%$ ulnar nerve injury reported in the literature can be prevented by clever placement using the medial mini-open technique (23-25). In our study, we observed iatrogenic ulnar nerve damage in 1 patient in each group, and this was below the literature average.

In a study conducted by Kwak-Lee et al. (26), the crossed pinning technique was performed on 47 patients, and it was reported that iatrogenic ulnar pin terrain was not observed in any of the patients. It was suggested that the medial pinning was safe to use when an appropriate technique was followed. It was also argued that although insertion of the medial pins leads to more extended operations, it does not result in a higher incidence of complications.

In another study comparing lateral and cross pinning by Maity et al. (27) 160 supracondylar fractures were evaluated; a statistically significant difference about complications was not found between the two groups. It was stated that if a standard technique is followed, there will be no difference in terms of effectiveness and safety.

In a meta-analysis conducted in 2018; considering the potential risks of lateral pinning with only two K-wires (risk of poor functional outcome) and crossed K-pins (risk of iatrogenic ulnar nerve injury), it was suggested the recommended technique for the treatment of pediatric distal humerus supracondylar fractures as the lateral access technique. Moreover, it was stated that the stability of the fracture fixation with a third k-wire placed laterally could be increased and that extra K-wire may be an option for surgeons who want to avoid the medial pinning. It was also indicated that additional protective measures should be taken for the ulnar nerve by surgeons who want a more stable structure with the cross-entry technique (11).

Our study has several limitations. First, it was a retrospective study, and no randomization was performed. Another limitation was that the number of patients included in the groups was not very high. Randomized and prospective studies involving bigger groups are needed for better results.

Consequently, when performed carefully, both techniques yield successful clinical results. When medial K-wire 
placement is desired, ulnar nerve iatrogenic injury can be minimized when the K-wire is placed using a careful mini-open technique. If the surgeon detects intraoperative instability, s/he should not hesitate to pin the medial K-wire in order to increase stability.

\section{Declarations}

The authors received no financial support for the research and/or authorship of this article. There is no conflict of interest.

This study was approved by the Erzurum Regional Training and Research Hospitals' local ethics committee (Date: 21.06.2021 No: KAEK 2021/12-199), and the study was conducted according to the Declaration of Helsinki 1975.

\section{REFERENCES}

1. Kwiatkowska M, Dhinsa BS, Mahapatra AN. Does the surgery time affect the final outcome of type III supracondylar humeral fractures? J Clin Orthop Trauma. 2018;9(Suppl 1):S112-5.

2. Mallo G, Stanat SJC, Gaffney J. Use of the gartland classification system for treatment of pediatric supracondylar humerus fractures. Orthopedics. 2010;33(1):19

3. Vaquero-Picado A, González-Morán G, Moraleda L. Management of supracondylar fractures of the humerus in children. EFORT Open Rev. 2018;3(10):526-540.

4. Omid R, Choi PD, Skaggs DL. Supracondylar humeral fractures in children. J Bone Joint Surg Am. 2008;90(5):1121-32.

5. Abbott MD, Buchler L, Loder RT, Caltoum CB. Gartland type III supracondylar humerus fractures: outcome and complications as related to operative timing and pin configuration. J Child Orthop. 2014;8(6):473-7.

6. Mostafavi HR, Spero C. Crossed pin fixation of displaced supracondylar humerus fractures in children. Clin Orthop Relat Res. 2000;(376):56-61.

7. Lee YH, Lee SK, Kim BS, Chung MS, Baek GH, Gong HS, et al. Three lateral divergent or parallel pin fixations for the treatment of displaced supracondylar humerus fractures in children. J Pediatr Orthop. 2008;28(4):417-22.

8. Otsuka NY, Kasser JR. Supracondylar Fractures of the Humerus in Children. J Am Acad Orthop Surg. 1997;5(1):19-26.

9. Lyons JP, Ashley E, Hoffer MM. Ulnar nerve palsies after percutaneous cross-pinning of supracondylar fractures in children's elbows. J Pediatr Orthop. 1998;18(1):43-5.

10. Blanco JS. Ulnar nerve palsies after percutaneous cross-pinning of supracondylar fractures in children's elbows. J Pediatr Orthop. 1998;18(6):824.

11. Na Y, Bai R, Zhao Z, Han C, Kong L, Ren Y, et al. Comparison of lateral entry with crossed entry pinning for pediatric supracondylar humeral fractures: A meta-analysis. J Orthop Surg Res. 2018;13(1).

12. Larson L, Firoozbakhsh K, Passarelli R, Bosch P. Biomechanical analysis of pinning techniques for pediatric supracondylar humerus fractures. J Pediatr Orthop. 2006;26(5):573-8.
13. Lee SS, Mahar AT, Miesen D, Newton PO. Displaced pediatric supracondylar humerus fractures: Biomechanical analysis of percutaneous pinning techniques. J Pediatr Orthop. 2002;22(4):440-3.

14. Slobogean BL, Jackman H, Tennant S, Z Gerard PS, Mulpuri K. Iatrogenic ulnar nerve injury after the surgical treatment of displaced supracondylar fractures of the humerus: Number needed to harm, a systematic review. J Pediatr Orthop. 2010;30(5):430-6.

15. Garra G, Singer AJ, Taira BR, Chohan J, Cardoz H, Chisena E, et al. Validation of the Wong-Baker FACES pain rating scale in pediatric emergency department patients. Acad Emerg Med. 2010;17(1):50-4.

16. Flynn JC, Matthews JG, Benoit RL. Blind pinning of displaced supracondylar fractures of the humerus in children. Sixteen years' experience with long-term follow-up. J Bone Joint Surg Am. 1974;56(2):263-72.

17. Kang S, Kam M, Miraj F, Park SS. The prognostic value of the fracture level in the treatment of Gartland type III supracondylar humeral fracture in children. Bone Joint J. 2015;97-B(1):134-40.

18. Boyd DW, Aronson DD. Supracondylar fractures of the humerus: A prospective study of percutaneous pinning. J Pediatr Orthop. 1992;12(6):789-94.

19. Zionts LE, Woodson CJ, Manjra N, Zalavras C. Time of return of elbow motion after percutaneous pinning of pediatric supracondylar humerus fractures. Clin Orthop Relat Res. 2009;467(8):2007-10.

20. Kumar V, Singh A. Fracture supracondylar humerus: A review. J Clin Diagnostic Res. 2016;10(12):1-6.

21. Hamdi A, Poitras P, Louati H, Dagenais S, Masquijo JJ, Kontio K. Biomechanical analysis of lateral pin placements for pediatric supracondylar humerus fractures. J Pediatr Orthop. 2010;30(2):135-9.

22. Swenson AL. The treatment of supracondylar fractures of the humerus by Kirschner-wire transfixion. J Bone Joint Surg Am. 1948;30(4):993-7.

23. Brown IC, Zinar DM. Traumatic and iatrogenic neurological complications after supracondylar humerus fractures in children. J Pediatr Orthop. 1995;15(4):440-3.

24. Royce RO, Dutkowsky JP, Kasser JR, Rand FR. Neurologic complications after k-wire fixation of supracondylar humerus fractures in children. J Pediatr Orthop. 1991;11(2):191-4.

25. Skaggs DL, Hale JM, Bassett J, Kaminsky C, Kay RM, Tolo VT. Operative treatment of supracondylar fractures of the humerus in children. The consequences of pin placement. J Bone Joint Surg Am. 2001;83(5):735-40.

26. Kwak-Lee J, Kim R, Ebramzadeh E, Silva M. Is medial pin use safe for treating pediatric supracondylar humerus fractures? J Orthop Trauma. 2014;28(4):216-21.

27. Maity A, Saha D, Roy DS. A prospective randomised, controlled clinical trial comparing medial and lateral entry pinning with lateral entry pinning for percutaneous fixation of displaced extension type supracondylar fractures of the humerus in children. J Orthop Surg Res. 2012;7(1). 